\title{
Fate of functional tricuspid regurgitation in aortic stenosis after aortic valve replacement
}

\author{
Dong Seop Jeong, MD, PhD, Kiick Sung, MD, PhD, Wook Sung Kim, MD, PhD, Young Tak Lee, MD, PhD, \\ Ji-Hyuk Yang, MD, PhD, Tae-Gook Jun, MD, PhD, and Pyo Won Park, MD, PhD
}

Objective: Functional tricuspid regurgitation (TR) is found not infrequently in conjunction with aortic stenosis. The aim of the present study was to evaluate the changes in TR and to identify the predictors of late progression after aortic valve replacement.

\begin{abstract}
Methods: We evaluated 354 patients who had undergone aortic valve replacement for aortic stenosis from January 1995 to December 2009. Patients with mitral regurgitation were excluded. Of the 354 patients, 54 had TR greater than mild. The mean follow-up duration was $4.4 \pm 4.3$ years (maximum, 15). The serial echocardiographic and clinical data were analyzed.
\end{abstract}

Results: No early mortality occurred, and the late cardiac mortality rate was 3.9\% (14 of 354). In the 48 patients with TR greater than mild, TR did not improve in $23(49.1 \%$ ) during the follow-up period. Freedom from cardiac mortality at 10 years was lower in those with TR greater than mild than in patients without TR $(61.6 \% \pm 16.7 \%$ vs $93.0 \% \pm 2.9 \%, P=.008)$. Left ventricular diastolic function correlated with right ventricular systolic pressure $(P<.001)$ and the degree of TR during follow-up $(P=.001)$. Multivariate analysis showed that postoperative atrial fibrillation (odds ratio, $6.8 ; P=.001$ ) and the aortic transprosthetic mean pressure gradient (odds ratio, $1.1 ; P=.028$ ) predicted late TR greater than mild.

Conclusions: Not only did TR in patients with aortic stenosis frequently persist after aortic valve replacement, it was progressive in some. This finding was associated with left ventricular diastolic dysfunction. A concomitant tricuspid valve procedure could be considered in selected patients with aortic stenosis to avoid late TR. (J Thorac Cardiovasc Surg 2014;148:1328-33)

Supplemental material is available online.

Functional tricuspid regurgitation (FTR) is common in patients with left-sided valve disease, and its development has been associated with increased morbidity and mortality after surgery. ${ }^{1,2}$ Several studies have reported on the risk factors related to FTR and its prognostic implications. ${ }^{3-5}$ Recently, guidelines have been issued for the management of FTR; however, the indications and optimal strategy have remained controversial. ${ }^{6-8}$ Most studies have been confined to tricuspid regurgitation (TR) associated with mitral valve disease, because this is more common than TR associated with aortic stenosis.

From the Department of Thoracic and Cardiovascular Surgery, Cardiovascular Imaging Center, Samsung Medical Center, Sungkyunkwan University School of Medicine, Seoul, Korea.

Disclosures: Authors have nothing to disclose with regard to commercial support.

Received for publication June 4, 2013; revisions received Sept 29, 2013; accepted for publication Oct 29, 2013; available ahead of print Dec 11, 2013.

Address for reprints: Pyo Won Park, MD, PhD, Department of Thoracic and Cardiovascular Surgery, Samsung Medical Center, Sungkyunkwan University School of Medicine, 50 Irwon-dong, Gangnam-gu, Seoul 135-710, Korea (E-mail: pwpark@skku.edu).

0022-5223/\$36.00

Copyright (c) 2014 by The American Association for Thoracic Surgery

http://dx.doi.org/10.1016/j.jtcvs.2013.10.056
In patients with aortic stenosis, TR is frequently a manifestation of right ventricular failure and a generalized distortion of ventricular geometry, especially in the setting of pulmonary hypertension and atrial fibrillation. ${ }^{9}$ Whether management of FTR associated with aortic stenosis should be undertaken just as is done for TR in mitral valve disease has not been determined, because its clinical significance and natural history are unknown. Because aortic valve replacement (AVR) for aortic stenosis is the most frequently performed surgery for valvular heart disease, FTR associated with aortic stenosis at AVR deserves the same careful consideration as FTR associated with mitral valve disease.

Our goals in the present study were to observe the changes in TR in those with aortic stenosis after AVR and its clinical effects. We also tried to identify the predictors for late progression of TR during the follow-up period.

\section{METHODS}

\section{Patients}

We reviewed the data from 448 consecutive patients with aortic stenosis who had undergone AVR from January 1995 to December 2009. Of the 448 patients, we excluded those with rheumatic aortic stenosis, combined mitral valve disease and/or tricuspid valve disease requiring valve procedures, and coronary artery disease. Patients with a history of cardiac surgery were also excluded; thus, 354 patients were enrolled. Of the 354 patients, 54 had FTR greater than mild (TR group) and 300 had no or trivial FTR (no-TR group). Our institutional review board approved the present 


\section{Abbreviations and Acronyms \\ AVR = aortic valve replacement \\ FTR = functional tricuspid regurgitation \\ NYHA $=$ New York Heart Association \\ $\mathrm{TMPG}=$ transprosthetic mean pressure gradient \\ $\mathrm{TR}=$ tricuspid regurgitation}

study and waived the requirement for individual consent from the patients or relatives.

\section{Operative Technique}

AVR was performed using standard cardiopulmonary bypass with bicaval cannulation. The basic surgical procedures and principles of AVR have been previously described and were maintained throughout the present study. ${ }^{10}$ Antegrade and retrograde blood cardioplegia were used for myocardial protection. Retrograde blood cardioplegia was infused by direct coronary sinus cannulation. Spaghetti or pledgeted 2-0 sutures were placed in a horizontal mattress fashion. The types of prostheses used were determined by surgeon preference. Modified ultrafiltration was routinely used.

\section{Follow-up}

Standard guidelines were used to define mortality and morbidity. ${ }^{11}$ An early event was defined as an event that occurred during the initial hospitalization (including $>30$ days), and all later events were defined as late events. Major adverse valve-related events included any structural or nonstructural prosthesis dysfunction, valve thrombosis, embolism, bleeding events, and prosthetic valve endocarditis. The postoperative outcomes and events after discharge were acquired by reviewing the medical records, by direct telephone interviews with the patients or their families, and from the National Registry of Births and Deaths. Follow-up data were available for 349 of the 354 patients $(98.6 \%)$. The mean follow-up period was $4.4 \pm 4.3$ years (maximum, 15 ).

Transthoracic echocardiography was performed before discharge and at $1,3,5$, and $>7$ years after surgery. The left ventricular end-systolic and enddiastolic dimensions were obtained in the parasternal view according to the American Society of Echocardiography guidelines. ${ }^{12}$ For 331 of 354 patients $(93.5 \%)$, echocardiographic assessments were performed not less than 1 year after AVR. Early diastolic mitral inflow and the mitral annular velocity ratio $\left(E^{\prime} / E\right)$ were measured by scanning the tips of the mitral valve leaflets with a pulse-wave Doppler unit. The aortic transprosthetic mean pressure gradients (TMPGs) were calculated using the Bernoulli equation. The degree of TR was assessed using the vena contracta width and the ratio of the maximal jet area to the corresponding right atrial area averaged on the parasternal and apical views. For statistical analysis, TR was graded from 0 to 4 . Late FTR was defined as TR greater than mild at any time postoperatively using color-flow Doppler analysis.

\section{Statistical Analysis}

For comparisons between the 2 groups, the $\chi^{2}$ test or Fisher exact test was used for categorical variables and the unpaired Student $t$ test for continuous variables. Repeated measures analysis of variance was used to compare the values at different measurement points. Cox regression analysis was used to identify the risk factors related to the clinical outcomes and FTR progression. The patients who had undergone tricuspid valve repair were excluded from this Cox regression analysis to remove the effect of valve repair on late FTR. The variables entered into the model were age, gender, New York Heart Association (NYHA) functional class, hemoglobin level, total bilirubin level, effective glomerular filtration rate, diabetes, hypertension, stroke, atrial fibrillation, bicuspid aortic valve, and the preoperative and postoperative echocardiographic parameters, including indexed the effective orifice area and $\mathrm{E}^{\prime} / \mathrm{E}$. If the $P$ value of a variable was $<.20$ on univariate analysis, the variable was entered into the multivariate analysis model. Survival and cardiovascular event-free curves were constructed to compare cardiac-related mortality and cardiovascular events in the 2 groups. The Statistical Package for Social Sciences, version 18.0 (SPSS, Chicago, Ill), was used for statistical analyses.

\section{RESULTS}

\section{Patient Baseline Characteristics and Operative Data}

The patient profiles are summarized in Table 1 . The mean age was $64 \pm 10$ years (range, 30-85), and the incidence of bicuspid aortic valve was $64.6 \%$ (248 of 384). The preoperative transaortic mean pressure gradient was $58.9 \pm 17.9$ $\mathrm{mm} \mathrm{Hg}$, and the $\mathrm{E}^{\prime} / \mathrm{E}$ ratio had increased to 15.6. The patients in the TR group had more risk factors and poorer cardiac function preoperatively than those in the no-TR group. More bioprostheses were implanted in the TR group than in the no-TR group, probably because of the age difference between the 2 groups. However, mean valve sizes were similar in the 2 groups. The incidence of bicuspid aortic valve and concomitant procedures was similar between the 2 groups. The operative data are summarized in Table E1.

\section{Clinical Outcomes}

No early mortality occurred; however, 18 patients $(5.1 \%)$ died late. Furthermore, the cardiac-related mortality rate for all study subjects was 3.7\% (13 of 354) and was greater in the TR group than in the no-TR group. The incidence of late morbidity was similar between the 2 groups (Table 2). No reoperation was performed for tricuspid valve disease during the follow-up period.

The overall cumulative survival rate at 10 years was $87.6 \% \pm 3.5 \%$. The freedom from cardiac-related mortality at 10 years was significantly lower in the TR group $(P=.008)$, although no intergroup difference was observed at 5 years (Figure 1). The age-adjusted cardiac death-free survival at 10 years was also lower in the TR group (hazard ratio, $3.9 ; 95 \%$ confidence interval, $1.2-12.2 ; P=.021)$. No intergroup difference was found for the freedom from cardiovascular events at 10 years $(85.4 \% \pm 3.5 \%$ for the TR group vs $88.9 \% \pm 4.8 \%$ for the no-TR group; $P=.298$ ).

Univariate analysis showed that older age $(P=.050)$, preoperative hypertension $(P=.024)$, and late FTR greater than mild at late follow-up $(P=.015)$ were associated with cardiac-related mortality. Subsequent multivariate analysis showed that preoperative hypertension (hazard ratio, 3.9; $95 \%$ confidence interval, $1.2-12.4 ; P=.023$ ) and late TR greater than mild (hazard ratio, $4.2 ; 95 \%$ confidence interval, 1.3-13.5; $P=.014$ ) were independent predictors of cardiac-related mortality. The preoperative NYHA functional class was the only predictor of cardiovascular events (hazard ratio, 2.083; 95\% confidence interval, 1.12-3.87; $P=.020)$. 
TABLE 1. Baseline patient characteristics

\begin{tabular}{lccc}
\hline \multicolumn{1}{c}{ Variable } & $\begin{array}{c}\text { TR group } \\
(\mathbf{n}=\mathbf{5 4})\end{array}$ & $\begin{array}{c}\text { No-TR group } \\
(\mathbf{n}=\mathbf{3 0 0})\end{array}$ & $\boldsymbol{P}$ value \\
\hline Age $(\mathrm{y})$ & $66.9 \pm 8.8$ & $63.0 \pm 10.3$ & .005 \\
Female gender & $27(50.0)$ & $97(32.3)$ & .014 \\
NYHA class & $2.3 \pm 0.6$ & $2.1 \pm 0.7$ & .009 \\
Hypertension & $22(40.7)$ & $120(40.0)$ & .919 \\
Diabetes mellitus & $13(24.1)$ & $41(13.7)$ & .063 \\
Stroke history & $0(0)$ & $9(3.0)$ & .365 \\
Atrial fibrillation & $11(20.4)$ & $26(8.7)$ & .015 \\
EuroSCORE $(\%)$ & $4.6 \pm 2.2$ & $5.8 \pm 2.6$ & .002 \\
Laboratory findings & & & \\
$\quad$ Hemoglobin $(\mathrm{g} / \mathrm{dL})$ & $12.6 \pm 1.7$ & $13.3 \pm 1.7$ & .002 \\
$\quad$ Total bilirubin $(\mathrm{mg} / \mathrm{dL})$ & $0.8 \pm 0.5$ & $0.7 \pm 0.5$ & .212 \\
$\quad$ Creatinine $(\mathrm{mg} / \mathrm{dL})$ & $1.1 \pm 1.3$ & $1.0 \pm 0.2$ & .132 \\
Echocardiographic & & & \\
$\quad$ findings & & & .006 \\
$\quad$ LA diameter $(\mathrm{mm})$ & $45.2 \pm 7.8$ & $41.9 \pm 6.8$ & .010 \\
$\quad$ Aortic valve area $\left(\mathrm{cm}^{2}\right)$ & $0.6 \pm 0.1$ & $0.7 \pm 0.2$ & .929 \\
$\quad$ AoV mean pressure & $58.5 \pm 18.2$ & $58.7 \pm 17.9$ & \\
$\quad$ gradient $(\mathrm{mm} \mathrm{Hg})$ & & & .002 \\
\hline E'/E ratio* & $19.5 \pm 8.2$ & $14.9 \pm 8.2$ &
\end{tabular}

Data presented as mean \pm standard deviation or $\mathrm{n}(\%) . T R$, Tricuspid regurgitation; $N Y H A$, New York Heart Association; $L A$, left atrium; $A o V$, aortic valve; $E^{\prime} / E$, early diastolic mitral inflow/mitral annular velocity. *Data acquired from February 2000 to March 2009.

\section{Echocardiographic Follow-up}

The postoperative echocardiographic results are presented in Table E2. The right ventricular systolic pressure was decreased after AVR in both groups, although this decrease was greater in the TR group. Aortic TMPG was also decreased after AVR, and the decrease was greater in the no-TR group. $E^{\prime} / E$ showed a tendency to a decline in

TABLE 2. Clinical outcomes

\begin{tabular}{lccr}
\hline \multicolumn{1}{c}{ Variable } & $\begin{array}{c}\text { TR group } \\
(\mathbf{n}=\mathbf{5 4})\end{array}$ & $\begin{array}{c}\text { No-TR group } \\
(\mathbf{n}=\mathbf{3 0 0})\end{array}$ & $\boldsymbol{P}$ value \\
\hline Early mortality & 0 & 0 & 1.000 \\
Late mortality & $7(13.0)$ & $11(3.7)$ & .011 \\
Cardiac-related mortality & $5(9.3)$ & $8(2.7)$ & .034 \\
Early complications & & & \\
$\quad$ Atrial fibrillation & $16(29.6)$ & $44(14.0)$ & .007 \\
PPM insertion & $1(1.9)$ & $2(0.7)$ & .392 \\
Bleeding & $1(1.9)$ & $4(1.3)$ & 1.000 \\
Stroke & $0(0)$ & $2(0.7)$ & 1.000 \\
Low cardiac output & $1(1.9)$ & $3(1.0)$ & .486 \\
$\quad$ Infection & $1(1.9)$ & $4(1.3)$ & 1.000 \\
Hospital stay (d) & $10.2 \pm 7.6$ & $11.1 \pm 7.0$ & .420 \\
Late complications & & & \\
$\quad$ Valve failure & $1(1.9)$ & $3(1.0)$ & .486 \\
Infective endocarditis & $1(1.9)$ & $3(1.0)$ & .486 \\
Hemorrhage & $2(3.7)$ & $2(0.7)$ & .112 \\
Embolism & $2(3.7)$ & $11(3.7)$ & .616 \\
\hline
\end{tabular}

Data presented as $\mathrm{n}(\%)$ or mean \pm standard deviation. $T R$, Tricuspid regurgitation; $P P M$, permanent pacemaker.

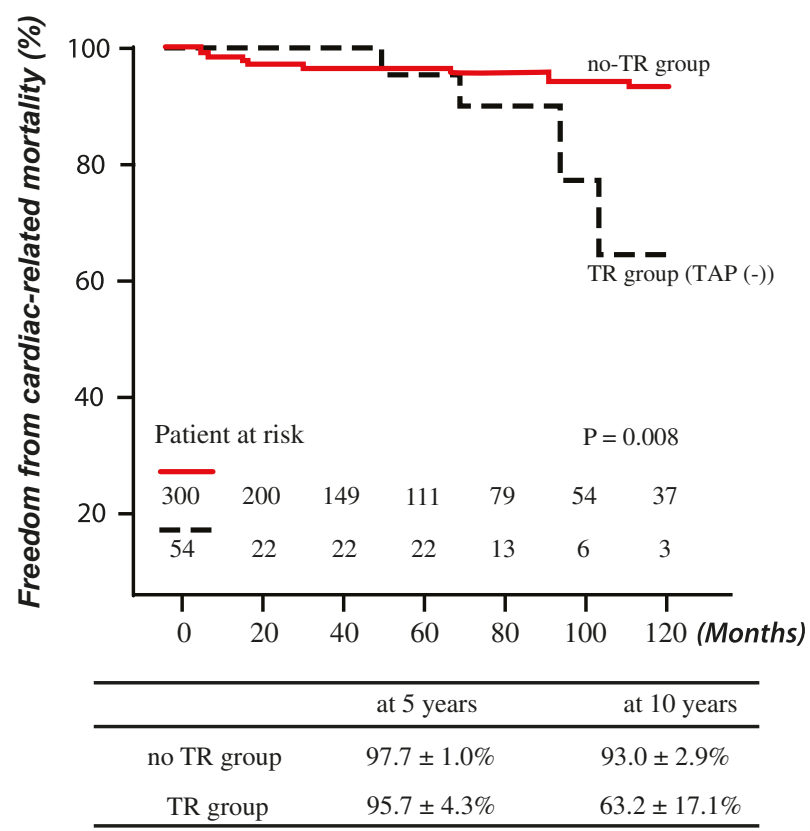

FIGURE 1. Freedom from cardiac-related mortality. $T R$, Tricuspid regurgitation; TAP, tricuspid annuloplasty.

the TR group, and no intergroup difference was observed during the follow-up period. The indexed aortic valve area measured using echocardiography during follow-up was similar between the 2 groups $(0.91 \pm 0.22$ vs $0.85 \pm$ $0.23, P=.08)$, and this was not associated with cardiacrelated mortality $(P=.369)$.

In the no-TR group, 45 of the 276 patients $(16.3 \%)$ showed at least mild TR at the late follow-up point. In the TR group, the mean TR grade had decreased after surgery $(2.2 \pm 0.4$ preoperatively vs $1.8 \pm 0.8$ at late follow-up, $P<.001)$. Also, 28 patients $(47.9 \%)$ showed spontaneous regression of FTR after isolated AVR during the followup period (Figure 2).

In all study subjects, the preoperative $E^{\prime} / E$ ratio correlated with the right ventricular systolic pressure $(\mathrm{r}=0.312, P<.001)$ and the TR degree during the follow-up period $(\mathrm{r}=0.228, P=.001)$. The $\mathrm{E}^{\prime} / \mathrm{E}$ ratio during the follow-up period also correlated with the right ventricular systolic pressure $(\mathrm{r}=0.212, P<.001)$ and TR degree $(\mathrm{r}=0.114, P=.049)$ during the follow-up period. The TR degree during follow-up also correlated with the aortic TMPG at the late follow-up point $(\mathrm{r}=0.157$, $P=.005)$. Multivariate analysis showed that preoperative TR, NYHA functional class, postoperative atrial fibrillation, and aortic TMPG at late follow-up were predictive of the progression of late FTR (Table 3).

\section{DISCUSSION}

The present study had 4 main findings. First, the incidence of FTR in patients with aortic stenosis requiring 


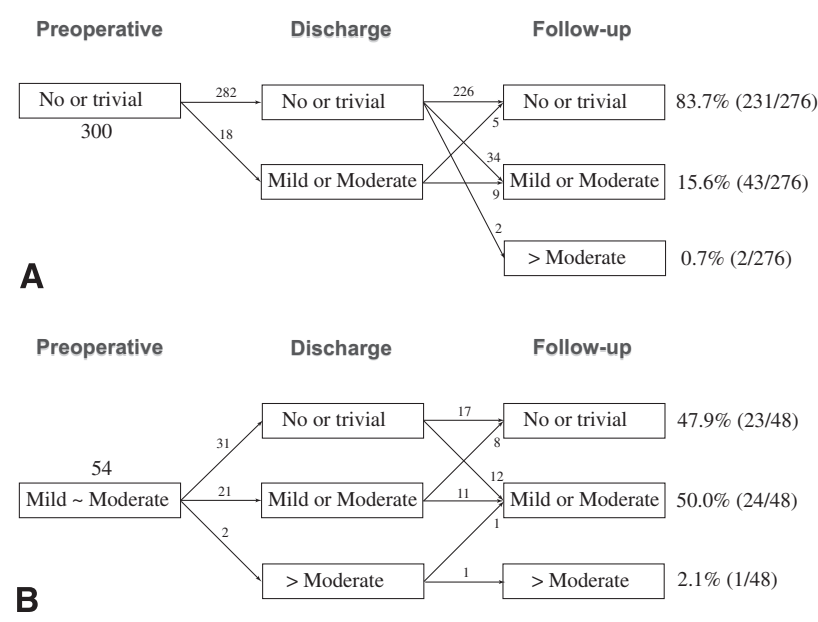

FIGURE 2. Changes in tricuspid regurgitation after aortic valve replacement. (A) Group without tricuspid regurgitation and (B) group with tricuspid regurgitation.

AVR was not uncommon, and this did not improve in one half of the patients with FTR after AVR. Second, FTR secondary to aortic stenosis was associated with poor clinical outcomes. Third, the preoperative $\mathrm{E}^{\prime} / \mathrm{E}$ ratio correlated with the right ventricular systolic pressure and TR degree during follow-up. Finally, the NYHA functional class, persistent atrial fibrillation, and aortic TMPG were predictive of the progression of late FTR.

FTR is relatively common in patients with left-sided valve disease and adversely affects cardiac morbidity and mortality. ${ }^{1,2}$ The management of FTR has evolved from conservative treatment in hope of spontaneous regression after left-sided valve surgery. Currently, tricuspid annuloplasty is recommended at left-sided valve surgery. ${ }^{13}$ However, it is still controversial, and most studies have only investigated FTR associated with mitral valve disease, because FTR associated with aortic stenosis is less common. ${ }^{14,15}$ In the present study, the incidence of FTR greater than mild in patients with aortic stenosis was $17.2 \%$ (61 of 354 ). No operative mortality occurred in either group; however, late cardiac-related mortality occurred more frequently in the patients in the TR group. This result suggests that FTR in those with aortic stenosis occurs during an advanced stage of valve disease and requires the same careful consideration as FTR associated with mitral valve disease.

Although it has been presumed that the mechanism of FTR in those with aortic stenosis is similar to that in mitral valve disease, the mechanism has yet to be determined. Pulmonary hypertension, which can result in right ventricular enlargement and right ventricular dysfunction, might be a major cause of TR by way of tricuspid annulus dilatation and the tethering of leaflets. Recently, the effect of pulmonary hypertension on the outcomes after AVR in those with aortic stenosis was reported by Melby and colleagues. ${ }^{16}$
TABLE 3. Predictors of tricuspid regurgitation greater than mild at late follow-up visit*

\begin{tabular}{|c|c|c|c|c|}
\hline \multirow[b]{2}{*}{ Parameter } & \multicolumn{2}{|c|}{$P$ value } & \multirow[b]{2}{*}{ OR } & \multirow[b]{2}{*}{$95 \% \mathrm{CI}$} \\
\hline & Univariate & Multivariate & & \\
\hline \multicolumn{5}{|l|}{ General } \\
\hline Age & .020 & .077 & & \\
\hline Gender & .027 & .059 & & \\
\hline Diabetes mellitus & .736 & & & \\
\hline Hypertension & .935 & & & \\
\hline $\begin{array}{l}\text { NYHA functional } \\
\text { class }\end{array}$ & .005 & .013 & 2.718 & $1.178-4.027$ \\
\hline $\begin{array}{l}\text { Atrial fibrillation } \\
\text { at follow-up }\end{array}$ & $<.001$ & .001 & 6.843 & $1.142-41.008$ \\
\hline \multicolumn{5}{|l|}{ Preoperative } \\
\hline Hemoglobin & .007 & .453 & & \\
\hline Total bilirubin & .444 & & & \\
\hline eGFR & .704 & & & \\
\hline \multicolumn{5}{|l|}{$\begin{array}{l}\text { Echocardiographic } \\
\text { findings }\end{array}$} \\
\hline \multicolumn{5}{|l|}{ LVESD } \\
\hline Preoperative & .784 & & & \\
\hline At follow-up & .689 & & & \\
\hline \multicolumn{5}{|l|}{ LVEDD } \\
\hline Preoperative & .276 & & & \\
\hline At follow-up & .813 & & & \\
\hline \multicolumn{5}{|l|}{ LVEF } \\
\hline Preoperative & .695 & & & \\
\hline At follow-up & .801 & & & \\
\hline $\begin{array}{l}\text { TR mild or more, } \\
\text { preoperatively }\end{array}$ & $<.001$ & .006 & 3.686 & $1.453-9.355$ \\
\hline \multicolumn{5}{|l|}{$\mathrm{E}^{\prime} / \mathrm{E}$ ratio } \\
\hline Preoperatively & .090 & .903 & & \\
\hline At follow-up & .224 & & & \\
\hline TMPG at follow-up & .008 & .028 & 1.052 & $1.006-1.101$ \\
\hline $\begin{array}{l}\text { Indexed aortic valve } \\
\text { area }\end{array}$ & .210 & & & \\
\hline $\begin{array}{l}O R \text {, Odds ratio; } C I \text {, confic } \\
\text { effective glomerular filtr } \\
L V E D D \text {, left ventricular e } \\
\text { tion; } E^{\prime} / E \text {, early diastolic } \\
\text { mean pressure gradient. } \\
\text { included in the analysis. }\end{array}$ & $\begin{array}{l}\text { nce interval } \\
\text { on rate; } L V I \\
\text { d-diastolic di } \\
\text { mitral inflou } \\
\text { Patients wh }\end{array}$ & $\begin{array}{l}Y H A, \text { New York } \\
\text {, left ventricul } \\
\text { nsion; } L V E F \text {, le } \\
\text { itral annular ve } \\
\text { nderwent tricus }\end{array}$ & $\begin{array}{l}\text { leart As } \\
\text { end-sys } \\
\text { ventricu } \\
\text { city; } T \Lambda \\
\text { d valve }\end{array}$ & $\begin{array}{l}\text { ociation; } e G F R \text {, } \\
\text { tolic dimension; } \\
\text { lar ejection frac- } \\
I P G \text {, transaortic } \\
\text { repair were not }\end{array}$ \\
\hline
\end{tabular}

Mutlak and colleagues ${ }^{17}$ also found that an elevated pulmonary artery systolic pressure was a strong determinant of TR severity; however, other factors, such as the demographic characteristics, mechanical factors, remodeling of right heart cavities, and atrial fibrillation are also likely to be involved. In the present study, we believe that the greater right ventricular systolic pressure observed in the TR group can be readily explained by these findings. Perhaps the most interesting finding of the present study was the close relationship between left ventricular diastolic dysfunction and FTR in association with aortic stenosis. The left ventricular filling pressure, a reliable parameter for evaluating left ventricular diastolic dysfunction, will commonly be elevated in 
patients with aortic stenosis. ${ }^{18}$ In our previous report, preoperative $E^{\prime} / E$, which represents the diastolic filling pressure, was the most important predictor of postoperative morbidity in patients with severe aortic stenosis. ${ }^{19}$ Casaclang-Verzosa and colleagues ${ }^{20}$ also reported that the preoperative $E^{\prime} / E$ ratio was the major determinant of pulmonary artery pressure in aortic stenosis. They suggested that if pulmonary hypertension cannot be explained by the severity of aortic stenosis, diastolic dysfunction should be considered and evaluated. According to Gjertsson and colleagues,$^{21}$ diastolic dysfunction progressed to a moderate or severe grade in patients with preoperatively normal or mild diastolic dysfunction at 10 years of follow-up, despite reductions in the left ventricular mass indexes. In our series, we found that the preoperative $\mathrm{E}^{\prime} / \mathrm{E}$ ratio and right ventricular systolic pressure at late follow-up correlated. We believe that left ventricular diastolic dysfunction in the presence of aortic stenosis might adversely affect right heart function and lead to aggravation of FTR.

Several studies have been undertaken to identify the predictors of persistent or aggravated FTR after left-sided cardiac surgery. Wang and colleagues ${ }^{22}$ reported that atrial fibrillation, a left atrial dimension $>60 \mathrm{~mm}$, and an interval between onset and surgery of $>20$ years were predictive of secondary TR occurrence after left-sided surgery. Matsuyama and colleagues ${ }^{23}$ showed that mild or greater $\mathrm{TR}$, atrial fibrillation, and a huge left atrial size preoperatively were risk factors for late FTR. However, the relation between pulmonary hypertension and later FTR remains controversial. ${ }^{24}$ In the present study, preoperative atrial fibrillation and aortic TMPG at follow-up were predictive of late significant FTR. Few studies to date have demonstrated a correlation between the TMPG and late FTR, although we have previously reported that the TR grade 5 years after aortic valve or double valve surgery correlated with the aortic TMPG. ${ }^{25}$ In terms of the aortic TMPG, late significant FTR might develop through the same mechanism in patients with stenotic aortic valve disease presenting with elevated left ventricular systolic pressure, although this hypothesis requires additional study. However, the indexed aortic valve area was not predictive of late FTR. Although the aortic valve area is known correlate with the TMPG, 78 patients with an indexed aortic valve area $<0.85$ had a TMPG of $<15 \mathrm{~mm} \mathrm{Hg}$ in our series. We thought that the effect of the TMPG on late FTR might be stronger than that of the aortic valve area. We believe that a concomitant tricuspid valve procedure should be considered if patients with aortic stenosis have atrial fibrillation, an elevated transprosthetic pressure gradient, or functional TR greater than mild to avoid late TR.

The present study had several limitations. First, the present study was limited by its retrospective nature. Second, the echocardiographic follow-up data were incomplete, for example, the mitral $\mathrm{E}^{\prime} / \mathrm{E}$ ratios were available only after
2000. A sampling bias might have been present in terms of the assessment of TR at the long-term follow-up visits. Furthermore, the parameters of right ventricular function, such as the right ventricular dimension or volumes, and preoperative tricuspid annular diameter were not included, because these parameters were not routinely measured in patients undergoing AVR in our institution. Third, the left ventricular filling pressure was not evaluated using invasive cardiac catheterization, which is the reference standard, and the $E^{\prime} / E$ values can by influenced by the left atrial pressure or left ventricular systolic and diastolic pressures.

\section{CONCLUSIONS}

FTR in association with aortic stenosis is frequently progressive despite isolated AVR, and it was associated with poor clinical outcomes. In addition to atrial fibrillation, left ventricular diastolic dysfunction and elevated aortic TMPG at the late follow-up point were related to the occurrence of late significant FTR.

The authors thank Joong Hyun Ahn, Sook-Young Woo, Shinyi Jang, $\mathrm{PhD}$, and Seonwoo Kim, $\mathrm{PhD}$, in the Division of Biostatistics, Samsung Medical Center, for statistical support. The authors also thank the database manager (Joomin Hwang) in our division.

\section{References}

1. Duran CM, Pomar JL, Colman T, Figueroa A, Revuelta JM, Ubago JL. Is tricuspid valve repair necessary? J Thorac Cardiovasc Surg. 1980;80:849-60.

2. Porter A, Shapira Y, Wurzel M, Sulkes J, Vaturi M, Adler Y, et al. Tricuspid regurgitation late after mitral valve replacement: clinical and echocardiographic evaluation. J Heart Valve Dis. 1999;8:57-62.

3. Sugimoto T, Okada M, Ozaki N, Kawahira T, Fukuoka M. Influence of functional tricuspid regurgitation on right ventricular function. Ann Thorac Surg. 1998;66: 2044-50.

4. Fukuda S, Song JM, Gillinov AM, McCarthy PM, Daimon M, Kongsaerepong V, et al. Tricuspid valve tethering predicts residual tricuspid regurgitation after tricuspid annuloplasty. Circulation. 2005;111:975-9.

5. Song JM, Jang MK, Kim YJ, Kim DH, Kang DH, Song JK. Right ventricular remodeling determines tricuspid valve geometry and the severity of functional tricuspid regurgitation: a real-time 3-dimensional echocardiographic study. Korean Circ J. 2010;40:448-53.

6. Dreyfus GD, Corbi PJ, Chan KM, Bahrami T. Secondary tricuspid regurgitation or dilatation: which should be the criteria for surgical repair? Ann Thorac Surg. 2005; 79:127-32.

7. Onoda K, Yasuda F, Takao M, Shimono T, Tanaka K, Shimpo H, et al. Long-term follow-up after Carpentier-Edwards ring annuloplasty for tricuspid regurgitation. Ann Thorac Surg. 2000;70:796-9.

8. Filsoufi F, Salzberg SP, Coutu M, Adams DH. A three-dimensional ring annuloplasty for the treatment of tricuspid regurgitation. Ann Thorac Surg. 2006;81: 2273-7.

9. Kim HK, Kim YJ, Park JS, Kim KH, Kim KB, Ahn H, et al. Determinants of the severity of functional tricuspid regurgitation. Am J Cardiol. 2006;98:236-42.

10. Sung K, Park PW, Park KH, Jun TG, Lee YT, Yang JH. Comparison of transprosthetic mean pressure gradients between Medtronic Hall and ATS valves in the aortic position. Int J Cardiol. 2005;99:29-35.

11. Akins CW, Miller DC, Turina MI, Kouchoukos NT, Blackstone EH, Grunkemeier GL, et al. Guidelines for reporting mortality and morbidity after cardiac valve interventions. Ann Thorac Surg. 2008;85:1490-5.

12. Lang RM, Bierig M, Devereux RB, Flachskampf FA, Foster E, Pellikka PA, et al. Recommendations for chamber quantification: a report from the American Society of Echocardiography's Guidelines and Standards Committee and the Chamber Quantification Writing Group, developed in conjunction with the European Association of Echocardiography, a branch of the European Society of Cardiology. J Am Soc Echocardiogr. 2005;18:1440-63. 
13. Vahanian A, Alfieri O, Andreotti F, Antunes MJ, Baron-Esquivias G, Baumgartner $\mathrm{H}$, et al. Guidelines on the management of valvular heart disease (version 2012): the Joint Task Force on the Management of Valvular Heart Disease of the European Society of Cardiology (ESC) and the European Association for Cardio-Thoracic Surgery (EACTS). Eur J Cardiothorac Surg. 2012;42:S1-44.

14. Calafiore AM, Iaco AL, Romeo A, Scandura S, Meduri R, Varone E, et al. Echocardiographic-based treatment of functional tricuspid regurgitation. J Thorac Cardiovasc Surg. 2011;142:308-13.

15. Yilmaz O, Suri RM, Dearani JA, Sundt TM III, Daly RC, Burkhart HM, et al. Functional tricuspid regurgitation at the time of mitral valve repair for degenerative leaflet prolapse: the case for a selective approach. J Thorac Cardiovasc Surg. 2011;142:608-13.

16. Melby SJ, Moon MR, Lindman BR, Bailey MS, Hill LL, Damiano RJ Jr. Impact of pulmonary hypertension on outcomes after aortic valve replacement for aortic valve stenosis. J Thorac Cardiovasc Surg. 2011;141:1424-30.

17. Mutlak D, Aronson D, Lessick J, Reisner SA, Dabbah S, Agmon Y. Functional tricuspid regurgitation in patients with pulmonary hypertension: is pulmonary artery pressure the only determinant of regurgitation severity? Chest. 2009;135: $115-21$.

18. Ommen SR, Nishimura RA, Appleton CP, Miller FA, Oh JK, Redfield MM, et al. Clinical utility of Doppler echocardiography and tissue Doppler imaging in the estimation of left ventricular filling pressures: a comparative simultaneous Doppler-catheterization study. Circulation. 2000;102:1788-94.
19. Chang SA, Park PW, Sung K, Lee SC, Park SW, Lee YT, et al. Noninvasive estimate of left ventricular filling pressure correlated with early and midterm postoperative cardiovascular events after isolated aortic valve replacement in patients with severe aortic stenosis. J Thorac Cardiovasc Surg. 2010;140: 1361-6.

20. Casaclang-Verzosa G, Nkomo VT, Sarano ME, Malouf JF, Miller FA Jr, Oh JK. $\mathrm{E} / \mathrm{Ea}$ is the major determinant of pulmonary artery pressure in moderate to severe aortic stenosis. J Am Soc Echocardiogr. 2008;21:824-7.

21. Gjertsson P, Caidahl K, Bech-Hanssen O. Left ventricular diastolic dysfunction late after aortic valve replacement in patients with aortic stenosis. Am J Cardiol. 2005;96:722-7.

22. Wang G, Sun Z, Xia J, Deng Y, Chen J, Su G, et al. Predictors of secondary tricuspid regurgitation after left-sided valve replacement. Surg Today. 2008;38: 778-83.

23. Matsuyama K, Matsumoto M, Sugita T, Nishizawa J, Tokuda Y, Matsuo T. Predictors of residual tricuspid regurgitation after mitral valve surgery. Ann Thorac Surg. 2003;75:1826-8.

24. Kim YJ, Kwon DA, Kim HK, Park JS, Hahn S, Kim KH, et al. Determinants of surgical outcome in patients with isolated tricuspid regurgitation. Circulation. 2009; 120:1672-8.

25. Cho YH, Jeong DS, Park PW, Park KH, Sung K, Kim WS, et al. Serial changes of hemodynamic performance with Medtronic Hall valve in aortic position. Ann Thorac Surg. 2011;91:424-31. 
TABLE E1. Operative characteristics

\begin{tabular}{lccc}
\hline \multicolumn{1}{c}{ Variable } & $\begin{array}{c}\text { TR group } \\
(\mathbf{n}=\mathbf{5 4})\end{array}$ & $\begin{array}{c}\text { No-TR group } \\
(\mathbf{n}=\mathbf{3 0 0})\end{array}$ & $\boldsymbol{P}$ value \\
\hline $\begin{array}{l}\text { Prosthetic type } \\
\quad \text { bioprosthesis })\end{array}$ & $36(66.7)$ & $152(50.7)$ & .038 \\
Valve size & $21.8 \pm 1.7$ & $22.1 \pm 1.8$ & .148 \\
Bicuspid & $30(56)$ & $194(64.7)$ & .309 \\
Transprosthetic MPG & $13.5 \pm 4.4$ & $13.4 \pm 4.8$ & .809 \\
$\quad($ mm Hg) & & & \\
Concomitant surgery & & $10(3.3)$ & .243 \\
$\quad$ Maze operation & $4(7.4)$ & $73(24.3)$ & .863 \\
$\quad$ Ascending aorta & $12(22.2)$ & & \\
$\quad$ procedures & &
\end{tabular}

TABLE E2. Echocardiographic results

\begin{tabular}{|c|c|c|c|c|c|}
\hline Variable & Preoperatively & At discharge & At follow-up & $P$ value $*$ & $P$ value \\
\hline $\operatorname{LVESD}(\mathrm{mm})$ & & & & & .025 \\
\hline TR group & $34.7 \pm 8.5$ & $34.9 \pm 8.1$ & $29.3 \pm 5.8$ & $<.001$ & \\
\hline No-TR group & $33.3 \pm 7.8$ & $32.9 \pm 6.7$ & $29.3 \pm 4.5$ & $<.001$ & \\
\hline$P$ value $\ddagger$ & .090 & .297 & .740 & & \\
\hline LVEDD (mm) & & & & & .124 \\
\hline TR group & $53.1 \pm 7.1$ & $50.4 \pm 6.5$ & $47.8 \pm 5.8$ & $<.001$ & \\
\hline No-TR group & $52.8 \pm 7.0$ & $49.3 \pm 6.2$ & $48.0 \pm 4.8$ & $<.001$ & \\
\hline$P$ value $\ddagger$ & .819 & .311 & .740 & & \\
\hline LVEF (\%) & & & & & .050 \\
\hline TR group & $56.2 \pm 13.5$ & $53.6 \pm 10.9$ & $62.6 \pm 9.0$ & $<.001$ & \\
\hline No-TR group & $60.1 \pm 11.8$ & $56.6 \pm 10.0$ & $63.3 \pm 6.4$ & $<.001$ & \\
\hline$P$ value $\ddagger$ & .034 & .087 & .651 & & \\
\hline \multicolumn{6}{|l|}{ TMPG (mm Hg) } \\
\hline TR group & $57.2 \pm 17.0$ & $13.6 \pm 4.6$ & $15.4 \pm 7.5$ & $<.001$ & .004 \\
\hline No-TR group & $58.9 \pm 18.0$ & $13.4 \pm 4.8$ & $12.6 \pm 5.4$ & $<.001$ & \\
\hline$P$ value $\ddagger$ & .724 & .800 & .005 & & \\
\hline \multicolumn{6}{|l|}{$\operatorname{LVMI}\left(\mathrm{g} / \mathrm{m}^{2}\right)$} \\
\hline TR group & $152.8 \pm 52.4$ & $139.2 \pm 45.4$ & $101.2 \pm 39.0$ & $<.001$ & .272 \\
\hline No-TR group & $151.8 \pm 48.7$ & $137.1 \pm 42.1$ & $102.8 \pm 28.9$ & $<.001$ & \\
\hline$P$ value $\ddagger$ & .928 & .900 & .690 & & \\
\hline RVSP (mm Hg) & & & & & $<.001$ \\
\hline TR group & $49.5 \pm 14.3$ & $36.5 \pm 7.0$ & $33.6 \pm 6.8$ & $<.001$ & \\
\hline No-TR group & $35.5 \pm 8.7$ & $30.7 \pm 5.5$ & $29.8 \pm 6.7$ & $<.001$ & \\
\hline$P$ value $\ddagger$ & $<.001$ & $<.001$ & .003 & & \\
\hline $\mathrm{E}^{\prime} / \mathrm{E}$ ratio & & & & & .007 \\
\hline TR group & $19.5 \pm 8.2$ & $19.5 \pm 6.0$ & $17.0 \pm 8.7$ & .238 & \\
\hline No-TR group & $14.9 \pm 8.2$ & $15.6 \pm 7.3$ & $15.3 \pm 8.7$ & .807 & \\
\hline$P$ value $\ddagger$ & .002 & .008 & .212 & & \\
\hline
\end{tabular}

